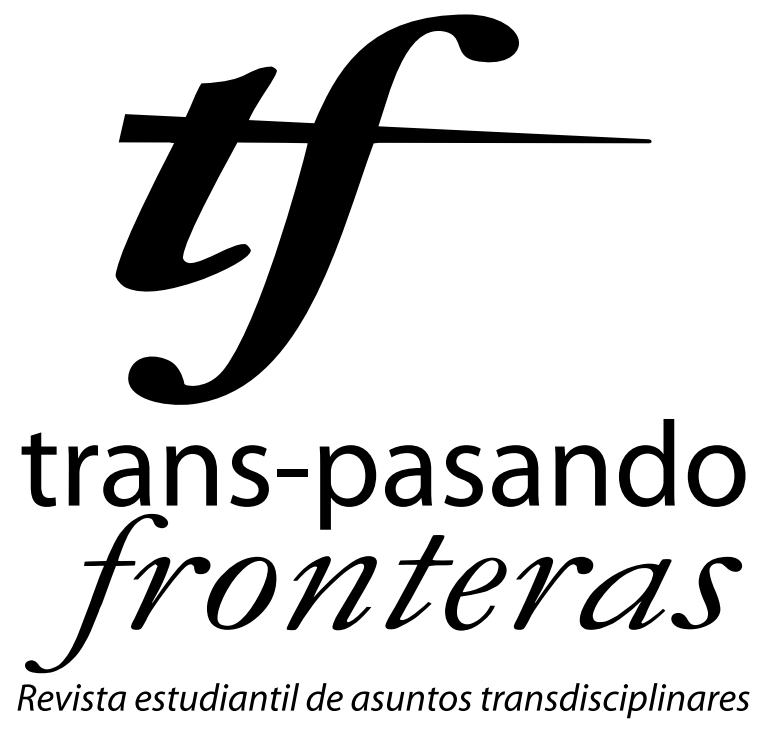

Una publicación de

Estudios

Interdisciplinarios

Jurídicos, Sociales

000 y Humanistas

ICESS

FACULTAD DE

DERECHO Y CIENCIAS

SOCIALES

然 UNIVERSIDAD 


\title{
El populismo abortado: los significantes vacíos en el gobierno del General Gustavo Rojas Pinilla
}

\author{
Guillermo Andrés Duque Silva* \\ (guillermoduque@unicauca.edu.co)
}

Artículo de revisión recibido el 01/08/2013 y aprobado el 15/12/2013.

\begin{abstract}
Como citar este artículo:
DUQUE SILVA, Guillermo Andrés (2013). "El populismo abortado: los significantes vacíos en el gobierno del General Gustavo de Gustavo Rojas Pinilla”. En: Trans-pasando Fronteras, Núm. 4, pp. 67-91. Cali, Colombia: Centro de Estudios Interdisciplinarios, Jurídicos, Sociales y Humanistas (CIES), Facultad de Derecho y Ciencias Sociales, Universidad Icesi.
\end{abstract}

\section{Resumen}

El artículo presenta un análisis del gobierno militar de Gustavo Rojas Pinilla como un intento de instauración populista. Apoyado en los planteamientos de Ernesto Laclau, el hilo conductor de este documento consiste en el seguimiento histórico-filosófico a la movilización de símbolos nacionalpopulares de Colombia, por parte del General Rojas Pinilla, como son el Sagrado Corazón de Jesús, Bolívar el Libertador y la Unidad Nacional. Elementos que en el discurso del General operaban como los significantes vacíos que articularían las demandas históricamente insatisfechas del pueblo colombiano, con su nuevo líder. Al final del texto se evalúan las razones por la que esta empresa de movilización de símbolos populistas fracasaría en Colombia.

* Estudiante de Maestría en Filosofía de la Universidad del Valle. Coordinador del Centro de Investigaciones Socio jurídicas de la Universidad Cooperativa de Colombia y docente en la Universidad del Cauca, sede norte. Miembro del grupo de investigación Praxis del programa de filosofía de la Universidad del Valle. 


\section{Palabras claves:}

Populismo, Significante vacío, Nacionalismo, Democracias Latinoamericanas.

\section{Introducción}

Este año 2013 se cumplen seis décadas desde que Colombia viviera el último intento $^{1}$ de instauración populista desde el poder en su historia como república. Los últimos dos años de gobierno del General Gustavo Rojas Pinilla se ajustan a lo que hoy podríamos llamar una empresa populista. La distancia temporal y las herramientas teóricas que intelectuales que, como Ernesto Laclau (2005), ofrecen para la interpretación de este fenómeno; hacen pertinente la indagación sobre la manera como edifica este complejo y particular sistema de gobierno.

Comprender la dictadura de Rojas Pinilla como un intento populista resulta problemático, ya que es innegable que los horizontes políticos del militar eran difusos, no obstante, el que quisiera tomar las riendas de la modernización del país por fuera de los límites del bipartidismo y reivindicar el advenimiento de una "Tercera fuerza" que resultara del binomio entre la Fuerzas Armadas y el pueblo, genera elementos suficientes para plantearse la pregunta, ¿El gobierno de Gustavo Rojas Pinilla, se acercó a la instauración de un populismo?

Ciertamente, las metas de esa "Tercera fuerza", y de su antecedente el MAN (Movimiento de Acción Nacional), como muy bien lo cita Álvaro Tirado Mejía, coinciden con las agendas de los grandes populistas latinoamericanos. Por ejemplo, este nuevo partido buscaría poner fin a la lucha de clases con la formación de sindicatos apolíticos y un programa agrario que beneficiara al campesinado, implementar un programa de educación gratuita y universal, modernizar la agricultura, garantizar la protección a las pequeñas empresas y sobre todo, intervenir de manera continúa en los negocios de los grandes capitalistas industriales, financieros y comerciales (Tirado, 1986:120).

No es el interés de esta investigación ahondar en las políticas y proyectos de modernización del Estado que se realizaron desde el gobierno de Rojas, sino indagar en la manera

1 Aunque la historia de Colombia ha registrado algunos intentos (todos fallidos) por acceder al poder por vía electoral de líderes y movimientos con rasgos que podríamos calificar genéricamente como 'populistas', este ha sido el único que se ha estructurado desde el ejercicio mismo del gobierno. Hay que recordar que olvidar que durante el proceso eleccionario de 1970, a través del partido Alianza Nacional Popular, ANAPO, el mismo Gustavo Rojas Pinilla hizo evidente su perfil populista. 
como se edificó simbólicamente la posibilidad de un régimen populista en Colombia. Por lo tanto, en el presente artículo se realiza un análisis de los símbolos y significantes vacíos que se movilizaron al finalizar el periodo de Rojas, recurriendo conceptualmente a la noción de cadena de equivalencias, inaugurada en la filosofía política por el argentino Ernesto Laclau.

Finalmente, se reúnen una serie de conclusiones frente a la caracterización del régimen rojista y los resultados de la identificación de demandas con los símbolos nacional-populares que se movilizarían en los últimos años de la dictadura.

\section{Metodología}

La investigación retoma uno de los temas cruciales en la historia política de Colombia en el siglo XX, referido a la dictadura militar de Gustavo Rojas Pinilla 19531957. Así, en el marco de la pregunta ¿por qué Colombia es uno de los pocos países latinoamericanos que no vivenció experiencias populistas?, esta monografía realiza una caracterización política y económica de la dictadura.

A partir de esa delimitación temática, se plantea como hipótesis que los esfuerzos políticos autonomistas de Rojas en la última fase de su gobierno y las constantes medidas nacionalistas y socializantes de la economía, en la totalidad de la dictadura, abren un paréntesis particular en la historia política colombiana. Sin embargo, la ausencia de condiciones que permitieran la transformación de la estructura económica y política del país, impediría para Colombia la posibilidad de cerrar ese paréntesis populista en su historia política, ya que el propósito de Rojas se desmorona al querer introducir a una realidad dominada por las representaciones históricas del bipartidismo y por un predominio del modelo económico liberal de desarrollo, elementos nacionales y populares de identificación política. De tal manera que el proyecto iniciado por Rojas es abortado por la insistencia opositora del bipartidismo tradicional, la Iglesia católica y los gremios económicos colombianos.

Para argumentar esta hipótesis, se estructura un plan de trabajo riguroso y claro, fundamentado en la recisión documental de la historiografía colombiana, que harto se ha ocupado de este tema, pero complementándolo el fundamento teórico del filósofo postfundacional Ernesto Laclau. El análisis del desarrollo simbólico del populismo en Rojas Pinilla se realiza a partir de fuentes de la época como es la publicidad 
política difundida por el régimen y las alocuciones del General Rojas Pinilla a través de la radio y la recién introducida televisión.

Frustraciones políticas de la dictadura: movilización de ideas y símbolos nacionales y populares

Es importante precisar como hipótesis que en los años finales a la dictadura, en las alocuciones políticas del General, transitan explícitas categorías abarcadoras que sobrepasan la identidad de partido y de clase social. Las referencias a la nacionalidad, a Cristo y a Bolívar, constituyen tropos lingüísticos que se exhiben como estrategias políticas de persuasión, para descalificar a los contrincantes políticos del bipartidismo tradicional, y a los defensores del sistema económico monopolístico y excluyente. En torno a estos elementos de identificación política, se tejen rasgos característicos de los regímenes nacional-populares, tales como la exaltación y convocatoria política al pueblo, la paz social como sustituto de los conflictos de clase y la figura creciente del líder carismático. De tal manera que en torno a los postulados suprapartidistas de Rojas, se nutre un discurso nacional y popular, que como hemos argumentado con anterioridad, no logró su cristalización práctica.

Contrario a los análisis que reducen este tipo de fenómenos al estudio de la manipulación y sugestión de las masas por parte de los líderes populistas, esta investigación plantea que la construcción de este nuevo discurso político, es fundamental para entender la emergencia misma del pueblo como actor histórico central.

El retorno al "pueblo" como categoría política, es planteado por Ernesto Laclau en La Razón populista, allí plantea que la identificación con un significante vacío es la condición sine qua non de emergencia de un pueblo. La noción de significante vacío hace referencia a ciertas denominaciones cuya plenitud y definición conceptual permanece constitutivamente ausente. Por ejemplo, sería una pérdida de tiempo intentar dar una definición positiva de "orden", o "justicia" -es decir asignarles un contenido conceptual, por mínimo que fuera- ya que se nombra una plenitud indiferenciada que no tiene ningún contenido conceptual en absoluto y constituyen términos, en el sentido más estricto, vacíos (Laclau, 2005:126).

De esta manera, la identificación con un significante vacío constituye un deno- 
minador común para la pluralidad de demandas insatisfechas que forman una cadena equivalencial. Según Laclau, el significante vacío mantiene vigente su condición en la producción discursiva de los actores políticos, en la medida que la necesidad de constituir un "pueblo", como parte que reclama ser el todo, empieza a tomar una forma real. Es decir el pueblo, como protagonista político, sólo surge cuando esa plenitud, representada en el significante vacío no es alcanzada y objetos parciales dentro de la sociedad (figuras, símbolos y objetivos) son conferidos de tal manera que se convierten en "los nombres de su ausencia" (Laclau, 2005: 131-150).

En el caso específico de esta investigación, encontramos que las constantes menciones del dictador a la "paz, justicia y libertad" no sólo constituyeron una particular consigna política, sino los significantes vacíos en torno a los cuales algunas figuras y símbolos nacionales y populares (Cristo, Bolívar y la Nación) fueron investidos de tal manera que se convirtieron en los nombres de estas tres ausencias. Sin embargo, como lo afirma Laclau, en la emergencia del pueblo, no hay nada de automático y siempre, entre otras posibilidades, puede fracasar en sus objetivos (Laclau, 2005: 249). Tal es el caso de la experiencia rojista, donde, como veremos más adelante, no se lograría la cristalización de una cadena de equivalencias.

Teniendo en cuenta lo anterior, es necesario definir los elementos discursivos que trazan una línea de continuidad histórica, en el transcurrir de la dictadura del General Rojas. Estos constituyen elementos contingentes y parciales que se reivindican como la totalidad de la comunidad y que en cada caso fueron abortados en su proceso de constitución como cadena de equivalencias.

\section{Cristo: la "paz social" como alternativa a la confrontación clasista}

En primer lugar, la evocación de Cristo como elemento retórico suprapartidista, se refiere a las pautas comunes de convivencia que se tejen como el "deber ser" de la vida nacional. La evocación a los preceptos cristianos de convivencia viene acompañada de una recurrente exaltación de lo sagrado y una impugnación de lo profano. Es decir, la mención a Cristo, en los discursos políticos del régimen, se esgrimía como un agente legitimador que dotaba de una mística religiosa las acciones propias y satanizaba las acciones del contrincante político, al considerarlas como depositarias de intereses diabó- 
licos y mezquinos. La evocación a Cristo como fuente moral e ideológica del régimen, fue una constante en las diferentes instancias de la dictadura, tanto en su primera fase de "gobierno de transición", como en la última etapa de régimen Nacional-popular. Varios de los escritos y discursos del General Rojas sirven de evidencia a esta situación:

\begin{abstract}
Convivencia Nacional
Aspiramos a que Colombia vuelva a ser el asiento de una democracia auténtica por el sentido cristiano de la vida, y a que los odios que procuraron tantas lágrimas, sean sustituidos por sentimientos de mutua comprensión que, sin impedir a nuestros partidos tradicionales el cumplimiento de sus programas doctrinarios, hagan de la lucha política no una feroz contienda, sino una batalla por el predominio de las ideas y por el mejor servicio del país. (Rojas, 2000: 457).
\end{abstract}

Estas referencias a los preceptos cristianos, eran constantes en la lucha por el capital cultural de la nación ${ }^{2}$, inclusive antes de la dictadura, tal como lo evidenció Laureano Gómez en su defensa del ideario católico. Igualmente, la relación que establece Rojas entre este dispositivo religioso con la identidad política popular, se proyectaría varios años después, en lo que sería el segundo intento de Rojas por culminar su proyecto. Así lo evidencia la siguiente foto de una de las estampas difundidas por la Alianza Nacional Popular en el año 1961, claro está que fuera del poder y en pleno ejercicio político bipartidista, en ejemplo claro del tipo de movilización de símbolos nacionales que realizó el General Rojas Pinilla a lo largo de su vida política.

Presumiblemente, en esos enfrentamientos es construido un enemigo que, al representarse en los odios del bipartidismo tradicional, consecuentemente simbolizaría un engendro diabólico y anticristiano frente al cual, sólo podía interpelar la protección del caudillo. La construcción política del enemigo, a partir de la evocación a valores que no comprometen exclusivamente la identidad partidista y que consecuentemente no implican la identidad de clase, es parte del Símbolo político de la época. De esta manera, cuando el contendor político le impugna ciertos rasgos de monstruosidad a su contrario, está

2 Refiriéndose a la evocación de elementos cristianos en el discurso político de Rojas, César Ayala, afirma que, "el General es producto consciente de una arraigada costumbre en la cultura política del país, que se considerada natural: la intromisión de la iglesia en los asuntos del Estado y en el devenir politico” (Ayala, 1996:55) 


\section{Imagen 1}

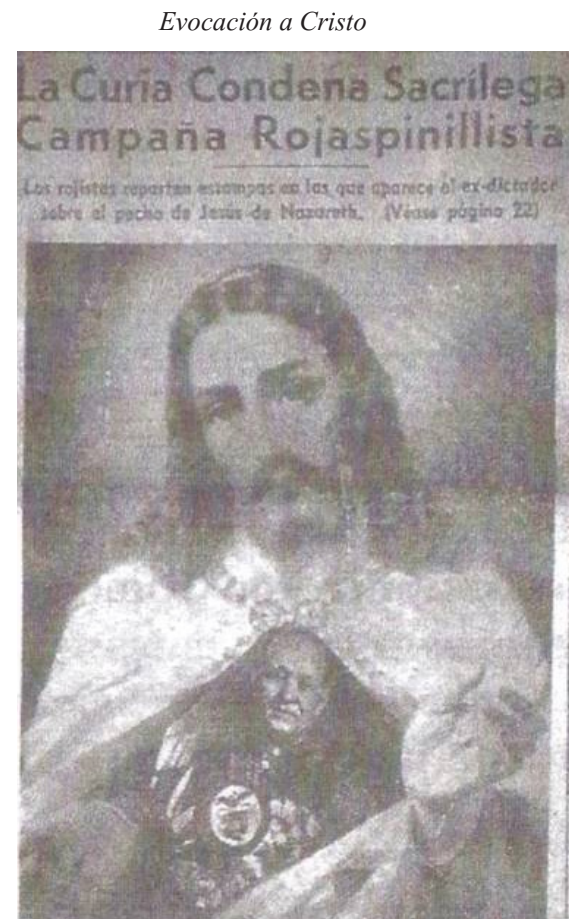

Fuente: (Ayala, 1996: 35)

reforzando su propia identidad política como representación de lo justo y lo sagrado, al mismo tiempo afirma ante la nación que su interpretación del conflicto social es la única y absoluta, en la medida en que sólo él, como líder, puede superarlo.

Partiendo de lo anterior, es posible afirmar que la situación se ajusta a lo que describe Octavio Ianni como proceso de politización y despolitización simultánea, ya que, en la medida que se politiza la alianza multiclasista que sostiene el régimen, se despolitizan las clases implicadas en ella. Así, la distinción entre el orden de lo sagrado y el caos de lo monstruoso, hace alusión a un valor multiclasista de negación y reconocimiento sincrónico, donde se impugna al contrincante como la monstruosidad, y se le otorga al locutor el derecho a satisfacer su deseo de protección, sin importar a qué colectividad política o grupo social haya pertenecido inicialmente.

De esta manera, la mención de Cristo en la producción discursiva del régimen acarrea como consecuencia la defensa del pacto multiclasista y multipartidista que sostenía política- 
mente el régimen. Bajo la estela de los preceptos cristianos, el gobierno pretendía solucionar pacíficamente los conflictos de partido y de clase. Sobre los primeros en diversas ocasiones manifestó que los liberales y conservadores pertenecientes al binomio Pueblo-Ejército, no debían dejar de serlo, simplemente debían anteponer el interés nacional y popular a los odios partidistas del pasado (Ayala, 1996:56). Con relación a la mediación de los conflictos de clase, podemos encontrar que el General enfocó sus esfuerzos en conseguir un sindicalismo de Estado que impidiera los enfrentamientos laborales en términos de clase. Esta es una característica de los gobiernos populistas de la región, pues este tipo de regímenes se abstienen de proponer una lucha de clases y como alternativa, su política se preocupa por buscar la "paz social" en un intento por eliminar este tipo de antagonismos.

En el caso de Rojas encontramos explícito ese objetivo, planteando su distancia ideológica con los postulados socialistas y comunistas:

\footnotetext{
Justicia Social

Así como no queremos la lucha sin cuartel de los partidos, tampoco queremos la lucha de clases, y aspiramos a ser los campeadores de una sociedad unida en la creación, en la distribución y en el goce de las riquezas. Quién dilapida trabajo, tiempo de trabajo y medios de trabajo, realiza un robo a la sociedad. El ideal no es que haya menos ricos, sino que haya menos pobres (Rojas, 2000: 456).
}

El régimen abogaría pues por la solidaridad de clases sociales en provecho de la unidad de la patria, lastimada por el recrudecimiento de la violencia partidista. Ante esta situación, los antagonismos de clase son comprendidos por el gobierno militar, como obstáculos a superar por medio de la reconciliación de clases y partidos, mediante el ejercicio de una "democracia cristiana":

\author{
Politica Social \\ Con el gobierno, inspirado en las ideas de justicia social cristiana, en una \\ sociedad que busca sinceramente la armonía de clases y en un territorio que \\ ofrece tan bastas posibilidades de bienestar, es inconcebible que haya gentes \\ sin abrigo o sin un pedazo de tierra. (Rojas, 2000: 456).
}

Sobre este asunto se refiere Juan Carlos Portantiero, (1998) aduciendo que es una 
característica de los regímenes nacional-populares. Según Portantiero, en este tipo de regímenes, el aparato estatal refuerza sus funciones arbitrales y acrecienta su peso como promotor del desarrollo y como regulador de la distribución en los conflictos de clase ${ }^{3}$.

Es importante concluir que la constante movilización de ideas y símbolos cristianos en el discurso político de Rojas Pinilla no logró materializarse en una acción política sostenida y coherente, donde se convocara al pueblo y a la unidad nacional en torno a este valor religioso de identificación. Los fracasos políticos representados en el MAN y en la Tercera Fuerza se debieron en gran medida, a la desautorización realizada por la Iglesia católica colombiana en representación del Cardenal Crisanto Luque y las editoriales del El Catolicismo.

Tal como lo explica César Ayala, la novedad política presentada por Rojas era que a su investidura de mandatario, se le suma la de "vocero de Dios" (Ayala, 1996:55), promocionando sus alternativas políticas al bipartidismo, como casi teocráticas, por encima del visto bueno de la Iglesia. Esto provocaría una reacción negativa en la alta jerarquía católica colombiana que, en septiembre de 1956, se dirigiría personalmente a Rojas para manifestar su desacuerdo con la proclamación de la Tercera Fuerza. Según el Cardenal Crisanto Luque, el juramento de fidelidad al nuevo partido realizado, en junio de ese año, en el estadio de fútbol el Campín no "consulta la justicia al abdicar las prerrogativas inalienables de la persona humana con la promesa de una obediencia ciega” (Ayala, 1996:56).

Así, bajo la etiqueta de profanador sacrílego de la fe católica, la maduración política de los símbolos nacionales y populares como la cristianidad es atajada principalmente por la Iglesia católica colombiana, con el respaldo de un amplio sector del bipartidismo tradicional que observaba con hostilidad la transformación política del régimen.

\section{Bolívar: relación dinámica entre el líder carismático y el pueblo}

En segundo lugar, se encuentra la apelación a Simón Bolívar como un elemento cardinal de identificación ideológica en el régimen rojista. En diferentes instancias de la dictadura, Rojas recurría a este elemento suprapartidista de filiación política, como una estrategia de persuasión que le brindaría un soporte de legitimidad a su empresa ideoló-

3 Este autor profundiza su estudio, argumentando que este tipo de regímenes resultan fundamentales en el proceso de constitución política de los sectores populares en Latinoamérica, presentando grandes diferencias con el modelo europeo que explica el fenómeno como un proceso progresivo, fundamentalmente de politización de la clase obrera. 
gica. Sin embargo, es en los años que comprenden la etapa final de su gobierno, donde encontraremos un mayor énfasis en la figura de Bolívar como soporte ideológico de los dos proyectos políticos de dicha fase: el Movimiento de Acción Nacional y La Tercera Fuerza.

De esta manera, la capitalización del pensamiento bolivariano como exclusividad gubernamental le permitía al dictador hacer referencia a un valor político de autoridad y protección legendarias. Este se presenta como parte integral de un ideal que sobrepasa los límites de los partidos tradicionales, los marcos de cualquier periodo de la historia republicana y las fronteras de la nación misma. En el discurso político de Rojas, la veneración a Bolívar, como padre de la república, hace que las menciones al Libertador se presenten como recordatorios de la responsabilidad que atañe, el "deber la libertad" a un prócer revolucionario. Así, la evocación de Bolívar como fuente ideológica, en los discursos que se presentan en esta investigación, tenía como fin brindar un soporte que legitimara irrevocablemente los argumentos de quien lo nombra. De los numerosos ejemplos que nos brinda Rojas para el periodo de su dictadura, se destaca el siguiente ejemplo:

Bolivar

Cuando niño aprendi a amar sus homéricas hazañas; en el ejército le admiré como militar; su pensamiento político me avasalla, y pronuncio su nombre con veneración. Bolivar lo fue todo: el precursor de la independencia, el tribuno de la revolución, el guerrero indomable, el legislador de geniales adivinaciones, el más grande de los estadistas del nuevo mundo.

A él vuelvo en estos momentos en que sopla vivificante por todos los ámbitos de la república el viento bueno de la paz, de la justicia y la libertad, para ratificarle el compromiso que adquirimos las fuerzas armadas, de no ser inferiores a nuestra tradición histórica; a él, presente en espiritu en este asiento de la vieja hidalguía castellana, me dirijo para pedirle que nos siga iluminando con su ejemplo, a fin de asegurar las conquistas en el orden de la solidaridad política y no quebrantar jamás esa unión que proclamara con la suprema aspiración de su espiritu; y a él arquetipo de gobernantes, de legisladores y de soldados, le pido en este día que nos asista con su inspiración patriótica, y cuyo único anhelo es el de trabajar sin desmayos al servicio de Colombia. (Rojas, 2000: 462). 
Como consecuencia política a la mención de Bolívar en los discursos, se buscaba la exaltación de la figura de Rojas como líder carismático, pues alrededor de la evocación

\section{Imagen 2}

Evocación a Simón Bolivar

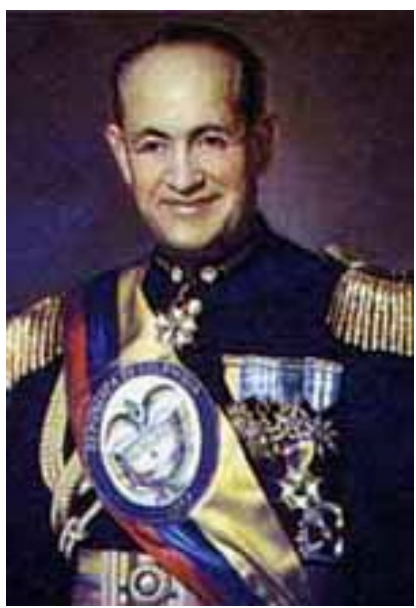

Fuente: (Rojas, 2000)

a Bolívar se presenta la construcción política de Rojas como el "Segundo Libertador". Esto se expresaba en la vestimenta del dirigente militar, que se asemejaba en demasía a los trajes de capa y espada con que se engalanaba el Libertador Bolívar (ver imagen 2).

En los regímenes populistas la figura del líder, carismático en el sentido weberiano, se caracteriza por interpelar y ser el depositario benefactor de toda la confianza del pueblo. En este orden de ideas, Rojas como el líder, sería el único actor político capaz de rearticular los elementos disociados en la experiencia de las masas, en otras palabras, la efigie preparada para reunir en un solo interés los objetivos políticos congregados en los círculos nacional-populares del MAN y La Tercera Fuerza en sus respectivos momentos.

Según Peter Worsley, (1969:91) en los populismos, "el líder es una personalidad catalizadora. Su función catalizadora consiste en convertir la solidaridad latente en acción política y en ritual activo”. La relación de dinámica representatividad entre el pueblo y su líder da nacimiento al Estado popular, como una entidad característicamente antiliberal propia de los regímenes populistas. Según Peter Wiles, "el Estado popular es el Estado que se vuelve visible y sensible a su jefe, el Estado dotado de voluntady de virtudes humanas, el Estado 
en el que corre no la linfa de la indeferencia y la neutralidad, sino la sangre del poder y de la justicia. El pueblo y su jefe son las dos entidades del régimen" (Wiles, 1998: 205).

Sobre el traslado de este asunto a las condiciones particulares del contexto colombiano de mediados del siglo XX, César Ayala, encuentra que el fenómeno carismático de Rojas se debe, en gran medida, a la continuidad y evolución de uno de los rasgos más característicos del Gaitanismo: el mesianismo. Según Ayala, "ahora los gaitanistas recurren preferencialmente a ese legado, encontrándolo reflejado y practicado por el presidente Mesías" (Ayala, 1996:35). De esta manera, es posible encontrar que el lugar mesiánico abandonado años atrás por el asesinato del líder liberal Jorge Eliécer Gaitán, deja un significante vacío que Rojas, desde el poder, intenta llenar con su discurso Nacional-popular. Tal como lo demuestra el contenido de los carteles que inundaron las ciudades colombianas en febrero de 1955, cuando el entonces Movimiento de Acción Nacional invitaba a la gente a salir a la calle:

\begin{abstract}
¡TRABAJADORES! Gaitán fue víctima de las oligarquías porque representaba los intereses del pueblo liberal y conservador; por la misma razón lo es el Presidente Rojas Pinilla. Viva el binomio Pueblo-Ejército; ;COLOMBIANOS! Las oligarquías son enemigas de la paz social y el binomio Pueblo-Fuerzas Armadas la sostendrá con su principal bandera de trabajo. Viva el presidente Rojas Pinilla, Viva la manifestación del 26 de febrero (Ayala, 1996:40).
\end{abstract}

Sobre la figura del líder en las experiencias nacional-populares, Alistair Hennessy, realiza un interesante trabajo, relacionando la construcción social del "Caudillo" rural con el dirigente populista urbano. Según Hennessy, "el éxito del líder populista depende de la habilidad con que sepa extender - del campo a la ciudad-la relación patronal y crear un sentido de parentesco entre él y las personas que de él dependen" (1969:48), En el caso específico de Rojas Pinilla, la labor de la Oficina de Propaganda y Prensa del Estado, ODIPE, del Servicio de Inteligencia Colombiano, SIC, y de la Empresa Nacional de Publicaciones, lograrían que la imagen del General, se mantuviera limpia y glorificada durante todo su régimen. Sería después de su caída cuando el proceso de desmitificación del líder popular daría sus frutos, en el largo enjuiciamiento realizado por congreso de la república al exdictador. 


\section{La Nación: convocatoria al pueblo como actor político fundamental}

En tercer lugar, en los discursos políticos del General Rojas las menciones nacionalistas, hacían referencia al conjunto de valores políticos que exaltaban el presente, el pasado y el futuro de la identidad patriota. Estas representaban un deseo de unidad nacional, presentado de manera quimérica desde los intereses de quien la evocaba.

De manera general, se puede definir que la referencia política a la nacionalidad, venía acompañada de la búsqueda de elementos que integraran, en un solo cúmulo de identidades, los valores y valoraciones de las clases sociales, étnias, partidos políticos y géneros, así como los modos de vida rurales y urbanos. Es común, como se presentaría en los años concernientes a la dictadura, que esta "integración identitaria" se realizara a partir de la exclusión de alguno o varios de estos elementos, privilegiando la exaltación de uno en particular. En el discurso político de Rojas las lesiones provocadas por un pasado de violencia, le permitía unir tanto a liberales como a conservadores, en torno a único sentimiento nacional y popular:

\footnotetext{
Convivencia Nacional

Aspiramos a que el pasado de comunes errores nos sirva en el presente para asentar, por obra del reconocimiento de las desdichas que acumularon en la historia nacional, los anchos bastimentos en que se alce una Colombia nueva, segura de su destino, justa en sus ambiciones de grandeza, respetada por el decoro de sus gobernantes, y digna de sobrevivir por la lealtad a la memoria de sus genitores (Rojas, 2000:456)
}

En resumen, esta es la referencia utilizada para designar los nodos identitarios que conectan, entre otras, la pertenencia a un territorio, a un pasado y a una raza. La interpretación de la nacionalidad por el régimen político dictatorial no variaría significativamente, si partimos de cierta resignación común frente a la fragmentación del territorio, la trasgresión al pasado y la presunta degeneración de la raza. Pues, en las movilizaciones políticas gobiernistas, tanto del MAN como de la Tercera Fuerza, las manifestaciones de sus adherentes, frente a cuestiones como la raza, dan cuenta de ciertas desgracias que, desde sus perspectivas, sería preciso corregir.

Según José Félix Vallejo, mancista conservador, de los colombianos se puede decir que, primero son "gentes aviesas" culpables de atizar la violencia partidista a los que no se les 
puede culpar por "su pobre cultura cívica", así es recomendable que el Estado intervenga para estimular "el desarrollo y cultivo de sus buenas inclinaciones y facultades naturales: que le depare un mejor nivel de vida" (Ayala, 1996:28). De tal manera, que la mención a la nacionalidad se presenta a través de una imagen lúgubre del país, que al exhibirse como una condición acongojada por un pasado violento, justifica el reclamo de protección e intervención pronta de su líder, diría Rojas: "A los pueblos no se les liberta de la rutinaria vulgaridad sino despojándolos de los sentimientos bajos y de la fruición en los goces inferiores” (1996:35).

En los últimos años de la dictadura la mención a elementos de la nacionalidad llevaría consecuentemente a exaltar la noción de "pueblo" como catalizador de ese cúmulo de identidades descrito con anterioridad. Según, César Ayala, el rescate del pueblo que hacía Rojas desde el poder, contribuyó a la construcción de la identidad política del régimen. Pues, poco tiempo atrás las masas populares habían sido ultrajadas gracias al asesinato del caudillo liberal Jorge Eliécer Gaitán (Ayala, 1996:34-41).

Así Rojas, con un lenguaje de optimismo y religiosidad, ganaría la responsabilidad de culminar los anhelos populares depositados en la ya mítica figura de Gaitán. De tal manera, que bajo el tutelaje del gobierno, el pueblo volvía a la tribuna pública como "la imagen mítica de una reunificación, deseada, pero lejana, de la sociedad" (Touraine, 1989:170).

En el caso específico de Rojas Pinilla, su deseo protector frente al pueblo hace que la movilización de símbolos que evoquen esta categoría social, estuviera constantemente acompañada por la mención a la Fuerzas Armadas, constituyendo la imagen emblemática de su última fase de gobierno: el binomio pueblo-ejército (ver imagen 3).

Si bien es cierto que el "rescate del pueblo", que inaugura Rojas en los últimos años de su gobierno, puede definirse por resaltar los lazos comunes de individuos "pobres" que están unidos por su condición de dominados, en contra de un grupo de "privilegiados", en la sociedad que intentamos describir, políticamente las clases sociales están escasamente delimitadas, pues, las identidades políticas se han organizado históricamente alrededor de los partidos políticos tradicionales. Por esta razón, es pertinente destacar que los actores sociales aglutinados en las evocaciones rojistas bajo la categoría de "pueblo”, son definidos por su rol político e ideológico más que por su posicionamiento de 


\section{Imagen 3}

Evocación a la Nación

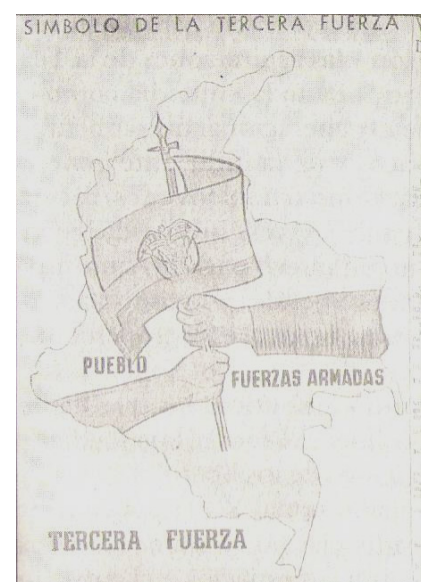

Fuente: (Ayala, 1996: 24)

clase $^{4}$. Esta definición se acoge a la argumentación de Alain Touraine, (1989) para quién los elementos de adscripción son más importantes que los de realización, en la definición política de los actores integrantes del "pueblo" en los regímenes Nacional-populares, ya que las identidades políticas que confluyen en esta categoría social, suelen referirse a elementos distintos a los de las clases sociales propiamente dichas.

Así, en el caso colombiano, la dictadura del General Rojas convocaba a un pueblo nutrido tanto por artesanos, campesinos y obreros como por oficinistas, profesionales, e intelectuales, pertenecientes en algunos casos, tanto al ala moderada del partido conservador, como al Gaitanismo y al socialismo. Estas características generales quedan evidenciadas en el juramento de fidelidad del pueblo ante la recién proclamada Tercera Fuerza en junio de 1956:

\section{Juramento de fidelidad a la Tercera Fuerza \\ Juráis a Dios y prometéis a la patria, defender la libertad y soberanía de Co- lombia hasta perder la vida si fuere necesario y luchar por la supremacía de la Tercera Fuerza hasta que los colombianos depongan los odios políticos al pie de la bandera nacional? SI, JURO... Ya Dios y la patria han recibido el}

4 Sin negar con esto que la sociedad que intentamos describir se estructura en términos de clase. 
juramento y la promesa que acabáis de hacer y os tomará en cuenta si dejáis de cumplir los deberes ciudadanos que os corresponden como integrantes del binomio Pueblo-Fuerzas Armadas. (Ayala, 1996:52)

Profundizando en la noción de pueblo, a que consecuentemente remite la mención a la nación en el discurso político de Rojas, encontramos que cumple con una de las características que Carlos Moscoso Perea, considera particulares de los populismos latinoamericanos. Ésta se refiere a la construcción discursiva e ideológica de un "nopueblo". Según Moscoso Perea, la relación antagónica del pueblo-no pueblo, permite al primero cargarse políticamente de una identidad, mientras impugna en el segundo, todo lo ajeno a la naturaleza popular (Moscoso, 1990:201).

En el caso específico a que se refiere esta investigación, la definición de no-pueblo que realiza Moscoso Perea, se condensa en los odios políticos de la violencia partidista y moviliza, en el proyecto político de Rojas, una resistencia popular al modelo liberal de desarrollo, al manejo elitista del Estado y a la influencia perniciosa del comunismo internacional.

De manera general, el no-pueblo en el discurso de Rojas, lo constituyen los agentes perturbadores de la paz nacional que mantenía el régimen:

\begin{abstract}
Trece de Junio
El 13 de junio no debe entenderse como el simple relevo de un régimen, sino como un acto de contrición de todo un pueblo... por eso he afirmado tantas veces que nadie personalmente puede capitalizar este movimiento. Pero que nadie tampoco pretenda desvirtuarlo, porque es Colombia entera, la grande la inmortal, la nuestra y la de nuestros hijos, la que sancionará a los destructores de su paz y de su porvenir" (Ayala, 1996:56)
\end{abstract}

Sin embargo, es conveniente aclarar que la convocatoria política al pueblo, realizada por Rojas en los últimos años de su mandato, fue interrumpida por el triunfo de la oposición liderada por la coalición bipartidista aglutinada en el Frente Civil. El derrocamiento de Rojas, no sólo implicó el retorno a la vida "democrática", sino una traumática interrupción, en lo que

5 Las comillas se refieren a la interpretación del Frente Nacional, como un pacto que si bien reestableció la institucionalidad democrática del país, puesto que también eliminó toda posibilidad de que emergiera un gobierno por fuera de los límites del bipartidismo tradicional. Al respecto ver (Ayala, 1996). 
Juan Carlos Portantiero llama, "proceso de constitución de las clases populares latinoamericanas en actores colectivos" (Pontantiero, 1998: 291-300). Frente a este proceso Portantiero, argumenta que las experiencias latinoamericanas, a diferencia del "rumbo clásico" de desarrollo progresivo de los sectores populares europeos, encuentran en los regímenes nacionalpopulares un foco sui generis para su fundación (Pontantiero, 1998: 294).

No obstante, como se ha argumentado hasta el momento, el proceso de convocatoria al pueblo en la experiencia rojista fue interrumpido, al no lograr que en la pluralidad de situaciones antagónicas que se presentaban en el país, fuera construida una identidad global a partir de la equivalencia de dicha multiplicidad de demandas sociales insatisfechas (Laclau, 2005). De tal manera que bajo las condiciones descritas con anterioridad, no es posible fijar con claridad la existencia de elementos que permitan ubicar al pueblo como un actor político emergente. Pues en la Colombia de mediados del siglo XX, no maduran las condiciones que bien podríamos hallar realizadas en contextos como el argentino, el chileno y el brasilero, por citar algunos ejemplos.

La maduración de cada una de las particularidades protopopulistas, mencionadas con anterioridad, se agudiza a medida que la dictadura se acerca a su final y como sabemos, fue brutalmente abortada por la resistencia del Frente Civil y el consecuente derrocamiento de Gustavo Rojas Pinilla el 10 de mayo de 1957.

\section{Conclusiones}

Colombia es uno de los pocos países latinoamericanos donde la constitución de los sectores populares en actores políticos colectivos, no cuenta con experiencias populistas como su eje de creación. A diferencia de países como Argentina, Chile y Brasil, el contexto político y económico colombiano se ha presentado, sin pausas, en términos intensamente liberales. Concretamente, en la mitad del siglo XX, cuando "el populismo tuvo su tiempo" (Palacios, 2001:11), no se lograron cosificar las condiciones necesarias (por ejemplo el vínculo entre las masas y un jefe), para que se materializara un proyecto populista sostenido y efectivo.

Ese es el caso del gobierno del General Gustavo Rojas Pinilla, para quien la respuesta a la convocatoria realizada al pueblo, como actor político fundamental, le fue interrumpida por los defensores del sistema político bipartidista tradicional, cuyo triunfo, expresado en los dieciséis años de estabilidad bipartidista (1958-1974), no logró despertar un entu- 
siasmo popular duradero (Pécaut, 2003:18) y condenó (o al menos aplazó) todo intento posterior de participación política de masas.

No obstante el fracaso del gobierno de Rojas, la experiencia vivida entre 1955 y 1957 dejó ver bajó qué significantes era posible iniciar la movilización del pueblo colombiano hacia su configuración como actor central de un populismo. Resulta importante indicar que la mención a Bolívar, a la Nación, y a Cristo supuso la evocación, implícita en muchos casos, de la cosificación de algunos de los rasgos característicos que identifican a los regímenes populistas y que han sido destacados por Ernesto Laclau bajo la categoría de significantes vacíos. El fracaso ante las élites no implica que el fenómeno deje de ser rico para explorar "la historia que no pudo ser": la historia en la que los sectores populares colombianos se transforman en un todo que da soporte ideológico y legitimidad política a un régimen populista. Por el contrario, si se considera que efectivamente, durante el periodo rojas hubo un intento por estructurar, al menos simbólicamente, un populismo, podremos dar luces con la "forma colombiana" de realizar este tipo de proyectos hegemónicos. Algo que, insisto, es en Colombia un misterio.

En la propuesta de Laclau (2005), el populismo se refiere a una forma específica de articulación de contenidos ideológicos de una sociedad, más que a un sistema político con rasgos objetivos claramente diferenciables ${ }^{6}$. Desde esa perspectiva podemos concluir que en efecto los últimos años del periodo rojista fueron un intento por articular los contenidos ideológicos y las demandas insatisfechas de un vasto sector de la nación colombiana, en consecuencia un intento populista. Pese a la naturaleza transicional del régimen militar, las condiciones de autonomía que exhibiría el gobierno, frente a los partidos tradicionales y los principales gremios económicos del país a partir de 1955, empezaron a impulsar componentes políticos propios de los regímenes nacional-populares.

Los símbolos Cristo, Bolívar y Nación dan cuenta de significantes propios de la dimensión del imaginario, son propiamente identificaciones que durante el régimen buscaba la coherencia con las históricas demandas insatisfechas del pueblo colombia-

6 Es por ello que en Laclau, lo populismos bien pueden ser derecha o de izquierda, no hay una sustancia que fundamente ontológicamente este fenómeno. Este asunto es criticado por Slavoj Zizek, (2004) para quien no porque un régimen o un líder invoque al 'pueblo' tenemos de hecho populismo, sino el fascismo y el nazismo serían variantes de populismo, así como Martin Luther King y por qué no Ronald Reagan, comparten un lugar como en la historia como líderes populistas. 
no: La Paz, el Padre protector y el mito fundacional de la Nación, en cuanto nombre de las identificaciones, vendrían a constituir el factor de mayor cohesión política en una sociedad fracturada por la violencia bipartidista.

En este proceso que Laclau explica apoyándose en la teoría del ‘trazo unario' de Lacan (1961-1962), en la cual las identificaciones (entre ellas la identificación política) con rasgos parciales le permiten al sujeto contarse como 'uno de' (Uno más de la familia, uno más de la oficina, etc.). En ese sentido, lo que estaba en juego en caso de Rojas, era la consideración de una parte de la sociedad Colombiana que, en tanto históricamente excluida del juego político, podría identificarse como el Pueblo del populismo. Se esperaba que alrededor de estos significantes vacíos, se lograra la adhesión de 'uno con otro' de los excluidos en un proceso encadenado de traducción de equivalencias. Este proceso no es consciente del sujeto y se logra precisamente porque el Símbolo enunciado, refleja un plano de lo Real a lo que no se logra nunca un acceso total: en el centro de esta intersección de lo Real con lo Simbólico y lo Imaginario, se encontraría según Laclau "un insondable agujero, que el sujeto llena con todo tipo de fantasías” (Gutiérrez, 2011: 154)

Ese es el momento genuinamente político, el instante en el que, alrededor de los símbolos movilizados, la particularidad hasta ahora excluida, asume el rol de re-emplazar la universalidad del establecimiento. En otras palabras, la lucha que inaugura la experiencia protopopulista de Gustavo Rojas Pinilla, consiste en demostrar quién era el verdadero heredero de un régimen cristiano, bolivariano y ante todo, colombiano: El bipartidismo o el rojismo.

La disputa como sabemos es perdida por Rojas, en la medida en que el bipartidismo 'logra comprender' que la lucha es ante todo ideológica y en ese terreno realiza sus mejores movimientos para deslegitimar al gobierno. Muestra de ello es que la constante movilización de ideas y símbolos cristianos en el discurso político de Rojas Pinilla, no logró materializarse en una acción política sostenida y coherente, donde se convocara al pueblo y a la unidad nacional en torno a este valor religioso de identificación. Los fracasos políticos representados en el MAN y en la Tercera Fuerza se debieron en gran medida, a la desautorización, permanente a partir de 1955, realizada por la Iglesia católica colombiana en representación del Cardenal Crisanto Luque y las editoriales de El Catolicismo.

Una hipotética explicación para este resultado, la podremos encontrar en el mismo andamiaje conceptual que nos brinda Laclau al referirse a la relación: Líder-Pueblo. Para el filósofo 
argentino, la identificación del pueblo con su líder opera de modo similar que sucede con los significantes vacíos, no se fundamenta en los supuestos rasgos carismáticos del 'Jefe supremo', sino en la falta del sujeto respecto a un objeto que colme su deseo (2005:230) es la mezcla de urgencia con ausencia del líder lo que fuerza la identificación del pueblo con él.

Aun cuando Laclau no lo explicita en la Razón populista, el vínculo es siempre inestable se constituye en la medida en que la urgencia y la ausencia se exacerban ad eternum y para ello se recurre a las acciones objetivas de gobierno. Las más importantes (en virtud de reforzar el vínculo del pueblo con sus significantes, entre ellos el Líder) son aquellas de las que se desprende la impugnación al Otro-no-pueblo. En el caso colombiano, las que enfrentaban el liberalismo económico y todo su andamiaje ideológico, con el modelo económico keynessiano.

A lo largo de la dictadura los esfuerzos por conseguir transformaciones en la economía colombiana fueron evidentes, y aunque no tuvieron mayor incidencia en la clásica organización piramidal de la estructura económica, las reformas impulsadas por el gobierno dan cuenta de un elemental proceso de modernización:

- Incipiente proteccionismo a la industria nacional.

- Restricciones y regulaciones estatales al sector comercial

- Inversión social amplia en educación, salud y vivienda, etc.

Desde el punto de vista del desarrollo económico, los avances en materia de políticas nacional-populares tuvieron un éxito relativo, pues la maximización de la función arbitral del Estado como promotor del desarrollo y como regulador de la distribución, tuvo como resultado un exitoso proceso de modernización. De tal manera que el régimen militar rojista, contrariando el mito liberal del desarrollo, descubriría en la intervención Estatal en la dinámica económica, el eje del proceso de modernización nacional. Sin embargo, las medidas económicas socializantes que pretendía llevar a cabo el General Rojas en su última etapa de gobierno, serían atajadas abruptamente por los representantes gremiales de la ANDI y FENALCO, entre otras asociaciones que se oponían a la radicalización del modelo de desarrollo nacional-popular que planteaba Rojas. Esta situación queda evidenciada al revisar los episodios de la caída de Rojas, donde los representantes 
gremiales desarrollarían un papel fundamental, como promotores del paro nacional y de las manifestaciones en oposición al régimen?

El experimento rojista fue una intuición y una aventura. Inevitablemente Rojas buscó su base de apoyo político en una población históricamente bipartidista, con la presunción de liderar un proyecto suprapartidista. Esto supone un quiebre radical en el conjunto de las representaciones colectivas del país, que con el liderazgo de Rojas solo tuvo alcances relativos ${ }^{8}$. La dinámica propia de las políticas económicas del régimen militar, redundó en una lógica mediática de la negociación, con la cual Rojas impulsaría sus reformas pagando, como contraprestación, la atenuación de sus pretensiones transformativas. Así, el carácter del régimen en cuestión de economía, se tornó forzosamente moderado. Lo suficiente para que se atenuar con hechos objetivos el proceso de identificación entre Líder y pueblo, que abría inaugurado en el plano de las subjetividades.

Mientras el Otro-no-pueblo, respondió al llamado de combate simbólico librado en la prensa y la radio, Rojas Pinilla no logró transgredir con hechos los límites objetivos de la estructura económica del país, el bastión predilecto del Otro-no-pueblo. Por el contrario, buscó reforzar a través de la recién inaugurada televisión y la Oficina de propaganda y prensa del Estado (ODIPE), la creencia en el significante vacío sin procurar 'llenarlo' fijando a través de la eficacia de su política un sentido al flujo de la cadena equivalencial de demandas del Pueblo, que permaneció a la espera de "acciones cristianas, bolivarianas y nacionales".

El momento de radicalización en que se encontraba el ambiente político no hacía viable la negociación mediática de políticas, en consecuencia, tal como lo explica Laclau, "Por estar 'vacios' esos significantes son susceptibles de ser hegemonizados" (Laclau, 1996a: 545). Aunque contrario a lo que dice Laclau, estos no fueron capitalizados de manera funcional a quien ostentaba el poder, sino que como lo hace notar Slavoj Zizek (2004) en Contingencia, hegemonía, universalidad. Diálogos contemporáneos en la izquierda, para quien el significante promovido a la dignidad de símbolo universal, (por ejemplo los relacionados con el régimen de Rojas bajo la connotación "supra-partidis-

7 Respecto al importante papel que jugaron los Clubes Sociales y los círculos de familias adineradas de la ciudad de Santiago de Cali, observar las referencias a "la conspiración de los Clubes" (Zawadski,1990:38).

8 Este cambio contó con grandes limitaciones, teniendo en cuenta que el país venía de una de las fases más intensas de violencia que haya vivido en toda su historia (1949-1953), así que es muy probable, que las diferencias partidistas, lejos de borrarse, se hubieran acentuado con el correr de la sangre. 
mo") nunca suprimen por completo el carácter específico de los particularismos que han quedado subsumidos (en este caso los relativos al bipartidismo) los cuales podrían irrumpir bloqueando la expansión de la cadena de equivalencias hasta re-significar la lucha por la hegemonía (Zizek, 2004: 95-139). En efecto, el llamado al "supra" partidismo, más que la anulación del bipartidismo, significó su suspensión temporal. Cualquier falla en el proyecto suprapartidista, traería como consecuencia el fortalecimiento del sistema sobre el cual se estaba autoreferenciado como alternativa.

Desde esa perspectiva, la corta vida política del Movimiento de Acción Nacional y, la derrota de la Tercera Fuerza ante la coalición del bipartidismo nacional, se explica en la medida en que Rojas no logró brindar un sentido que le fuera funcional a los símbolos que movilizó, labor que sí materializó el llamado en el Frente Civil que se organizó en su contra. De tal manera que el proceso liderado por Rojas Pinilla, al que acertadamente César Ayala Diago ha llamado "rescate del pueblo", fue escabrosamente interrumpido por las fortuitas coaliciones del bipartidismo tradicional, inclusive apoyándose en los mismos significantes vacíos con los que Rojas llamó al pueblo a la tribuna pública9 .

En resumen, aunque las características del régimen y discurso político rojista presentan, a partir de 1955, algunas similitudes con los fenómenos populistas latinoamericanos, la intención de canalizar las fuerzas políticas a su favor en la constitución de un tercer partido, no se concretaría exitosamente. Los significantes que inaugura el régimen, permanecen vacíos ante la ausencia de medidas políticas que hicieran de la retórica, una política hegemónica populista. En consecuencia, el triunfo del Otro-no-pueblo, se concreta en el pacto bipartidista que eliminó la participación de otros partidos por dieciséis años.

\section{Bibliografía}

AYALA DIAGO, César. (1996). Resistencia y oposición al establecimiento del Frente Nacional; los origenes de la Alianza Nacional Popular, ANAPO. Colombia 1953-1964, Bogotá: Colciencias.

9 Cabe recordar que figuras como Guillermo León Valencia y Alberto Lleras Camargo, calificaron permanentemente el Frente nacional a partir de afirmaciones universalistas como, "El retorno a la Democracia", "la Paz pactada que sanará al país y contendría la amenaza comunista” entre otras. Al respecto ver La explosión del populismo en Colombia. ANAPO y la participación politica durante el Frente Nacional de César Ayala Diago (2011). 
AYALA DIAGO, César. (2006). El populismo atrapado, la memoria y el miedo: El caso de las elecciones de 1970. Colombia: La Carreta Editores.

AYAlA DIAGO, César. (2011). La explosión del populismo en Colombia. ANAPO y la participación política durante el Frente Nacional. Colombia: Editorial de la Universidad Nacional del Colombia.

CANOVAN, Margaret. (1981). Populism. Londres, Inglaterra: Junction Books Ltd..

DONADÍO, COPELLO, Alberto. (1991). "Gobierno de Gustavo Rojas Pinilla”. En: Melo, Jorge Orlando (Dir. Académ.) Gran Enciclopedia de Colombia. Colombia: Editorial Pinter Latinoamericana.

FUNES, Silvina y Damián Saint-Mezard. (2002). "El Populismo en Latinoamérica". En: Vallespín Fernando (editor) Historia de la Teoría política, No. 5; Rechazo y desconfianza al proyecto ilustrado. Madrid, España: Alianza Editorial.

GALVIS, Silvia y Alberto Donadío. (1988). El Jefe Supremo. Bogotá: Editorial planeta.

GERMANI, Gino. (1962). Política y Sociedad en una época de transición, Buenos Aires, Argentina: Paidós.

GUTIÉRREZ VERA, Daniel (2011). "Ernesto Laclau: El populismo y sus avatares. Íconos”. En: Revista de Ciencias Sociales, No 40, pp. 151-16. Quito, Ecuador: FLACSO.

HENNESSY, Alistair (1969). "América Latina”, En: Ghita Ionescu y Ernst Geller (compiladores), Populismo: Sus significados y características nacionales. Buenos Aires, Argentina: Amorrortu Editores.

IANNI, Octavio (1975). La formación del Estado populista en América Latina. México: Ediciones Era.

IPOLA, Emilio de y Juan Carlo Portantiero (1986). "Lo Nacional popular y los populismos realmente existentes". En: Labastida Julio (coord.), Los nuevos procesos sociales y la teoría política contemporánea. México: Siglo XXI Editores.

IRIARTE Alfredo. (1989). "El golpe de opinión de Rojas Pinilla". En: Mallarino de Rueda, Silvia (Coord. cient y académ.) Historia de Colombia. Barcelona, España: Editorial Salvat.

LACLAU, Ernesto (1980). Política e ideología en la teoría marxista. Capitalismo, fascismo, populismo. México: Siglo XXI Editores.

LACLAU, Ernesto (2005). La razón populista, México: FCE. 
MOSCOSO PEREA, Carlos (1990). El populismo en América Latina, Madrid: Centro de Estudios Constitucionales.

PALACIO, Marco (1971). El populismo en Colombia, Medellín: Ediciones El Tigre de Papel.

PÉCAUT, Daniel (2003). Violencia y Política en Colombia: Elementos de reflexión. Medellín, Colombia: Hombre Nuevo Editores.

PÉCAUT, Daniel (2001). Orden y Violencia: Evolución Socio-política de Colombia entre 1930 y 1953. Bogotá: Editorial Norma.

PORTANTIERO, Juan Carlos (1998). "Notas sobre Crisis y Producción de Acción Hegemónica". En: Julio Labastida (coord.) Hegemonía y alternativas politicas en América Latina. México: Siglo XXI Editores.

ROJAS DE MORENO, María Eugenia. (2000). Rojas mi padre. Bogotá: Imprenta Nacional De Colombia.

SÁNCHEZ, Gonzalo. (1983). Bandoleros, Gamonales y Campesinos: El caso de la violencia en Colombia. Bogotá, Colombia: Ed. El Áncora.

TOURAINE, Alain. (1989). América Latina; politica, y sociedad. Madrid: Espasa Calpe.

URÁN, Carlos. (1983). Rojas y la manipulación del poder. Bogotá: Carlos Valencia Editores.

VÉLEZ, Humberto (sf.). De Gómez a Rojas o Los Nuevos Rostros del Poder 19491953. (Borrador). Santiago de Cali.

WILES, Peter (1969). "Un síndrome, no una doctrina: Algunas tesis elementales sobre el populismo". En: Ghita Ionescu y Ernst Geller (compiladores), Populismo: Sus significados y caracteristicas nacionales. Buenos Aires, Argentina: Amorrortu Editores.

WORSLEY, Peter (1969). "El concepto de populismo”. En: Ghita Ionescu y Ernst Geller (compiladores), Populismo: Sus significados y características nacionales. Buenos Aires, Argentina: Amorrortu Editores.

ZAWADSKI, Clara (1990). Club Campestre de Cali: Sesenta años con Cali y su gente. Santiago de Cali, Colombia: Sáenz Editores.

ZIZEK, Slavoj (2004). “¿Lucha de clases o posmodernismo? ¡Sí, por favor!”. En: Contingencia, hegemonía, universalidad. Diálogos contemporáneos en la izquierda, con: Judit Butler y Ernesto Laclau. Buenos Aires: FCE 
Referencias de las Imágenes

AYALA DIAGO, César. (1996). Resistencia y oposición al establecimiento del Frente Nacional; los orígenes de la Alianza Nacional Popular, ANAPO. Colombia 19531964, Bogotá, Colombia: Colciencias.

ROJAS DE MORENO, María Eugenia (2000). Rojas mi padre. Bogotá, Colombia: Imprenta Nacional de Colombia. 